\title{
Gender Inequality In Academia: Evidences From Nigeria
}

\author{
Christiana O. Ogbogu, Obafemi Awolowo University, Nigeria
}

\begin{abstract}
Universities and other institutions of higher education in Nigeria see themselves as liberal and open-minded. They support social movements that encourage principles of democracy and social justice, yet their mode of governance is male dominated and patriarchal. This study, therefore, identified the causes of gender inequality in academia and the implications on the academic development of females in the university system. This study was considered necessary because of the observed anomaly in the composition of academic staff in Nigerian universities. Data for the study were obtained from both primary and secondary sources. Primary data were obtained through the in-depth interview of sixty (60) purposively selected male and female academic staff occupying key positions in three (3) Federal universities located in southwestern Nigeria. The study revealed that the recruitment and selection practices in the universities neither stressed male ideology nor discriminated against women; rather merit was the yardstick for acceptance into the profession. It was found that lack of mentoring, poor remuneration, women's lack of interest in academia, family responsibilities, the lengthy period of training, and the ideology that women should have low career aspirations due to traditional roles ascribed to them, accounted for the observed disparity in academia. The implication of this disparity on the academic development of women is the general reduction in their research output and the perpetuation of their low status in academia. The study concluded that appropriate institutional adjustments and affirmation action programmes are necessary to meet women's demands of equality and improve retention.
\end{abstract}

Keywords: Gender Inequality; Academic Development; Academia; Nigeria; University

\section{INTRODUCTION}

$\mathscr{I}$ $\mathrm{n}$ spite of the advances which women have made in many areas of public life in the past two decades, they are still a long way from participating on the same footing in academia as men. The global picture is one of men outnumbering women in research and publication. Female Deans and Professors are a minority group, while female Vice-Chancellors are rare (Poole, 2005). Women in Nigerian universities hold less than 35 percent of academic posts. They are mainly represented in the lower and middle level academic positions and their participation relative to men decreases at successive levels. Despite the fact that the Nigerian university system is over sixty years old, there are still evidences of low female participation as academic staff. For instance, in 2006 University of Ibadan had an academic staff strength of 3081, out of which 2574 were males and 507 females, Obafemi Awolowo University had 1207 academic staff members out of which 210 were females and University of Lagos's academic staff strength was 813 out of which 250 were females. Engineering, medicine and the science disciplines remain strongly dominated by men, while the highest concentrations of women are found in the humanities and social sciences (Ogbogu, 2006).

The problem is that of a leaky-pipeline which is caused in part by the practices that produce gender imbalance. For instance, women do not receive as much information as men do about how to be successful. Literature suggests that men and women want the same things from their jobs, but men are more willing than women to forgo a balanced life and are thus empowered to dominate academia. It is however not a wise policy decision to have those who forgo a balanced life dominate. This is evidence that entrenched institutional practices stifle women's full potential to advance in academia. 
Furthermore, women frequently face cultural barriers which emanate from the way society view the roles and the expectations ascribed to them. In addition, their dual responsibilities as wife and mother perpetuate their under-representation in academia. Consequently, they progress haltingly in academia, taking breaks off to rear children and in the process suffer great tension in their attempts to reconcile academic and domestic roles. In view of this, Winslow (2010) suggests the need for husbands to support their wives so that they can be empowered to effectively manage their dual role and maintain a balanced career.

The rate at which women rise alongside their male colleagues is slower and Okurame (2008), attributes Lack of strong research record and publications as factors responsible for this and for the clustering of female academics at the lower levels of the academic career ladder. Since universities are expected not only to produce high level manpower, but also to make positive contributions to the overall development of the country, it therefore becomes increasingly necessary to build a congenial academic environment where the talents of men and women are equally harnessed to enhance sustainable development.

This paper therefore identifies the causes of gender inequality in academia and its implications on the academic development of women in Nigerian universities. This study is considered necessary because of the observed anomaly in the composition of academic staff in Nigerian universities particularly at a time when major efforts have been made at institutionalizing gender equality policies in most universities worldwide.

\section{REVIEW OF LITERATURE}

Universities are noted for the development of expertise and high level manpower necessary for economic growth and national development. Universities provide skilled and professional personnel for the civil service and private sector organizations. This requires that women play critical roles as intellectuals, policy-makers, planners, decision-makers and contributors to the development process (Morley, 1999). In Nigeria, however, the academic profession has always favoured men. This is because most females contend with a wide range of factors which do not allow them to advance on the job. Literature affirms that gaining an academic position in Nigerian universities is challenging for women and maintaining it is more difficult. Although some of them have made impressive achievements, they remain a marginalized minority (Ogbogu, 2009a).

Gender inequality in academia is an important issue not only in Nigeria, but all over the world. The situation in the United Kingdom, Netherlands, Spain, India and Switzerland reflects a high under-representation of academic women in professorial positions and in science and technology disciplines. The percentage of women across commonwealth universities of full-academic staff status ranges from 9.5 percent in Ghana to just over 50 percent in Jamaica. The pattern that emerges suggests that woman get stuck at the lower levels of the academic career structure (Ogbogu, 2009b).

The university has been perceived as traditionally elitist and patriarchal in its workplace culture, structure and value. Luke (1997) asserted that the clustering of women in the lower ranks is the result of universities' conservative traditional cultures and systems. He referred to it as overt and covert "glass-ceiling" that impedes academic women's career paths. The 'glass-ceiling' manifests in the form of male managerial style and informal organizational cultures which he referred to as the 'old boys club'. Kan (2007) supports this view by arguing that workplace culture, and specifically the reward structure, shape preferences for work and account for the gender gap in academia. Furthermore, Bailey (1999) affirmed that universities reproduce gender differences via their internal structure and everyday practices. He further attributed the disadvantageous position of women in the universities to the organizational structure which, according to him, shapes and defines the behaviour of woman. Since the problem rests in the structure, the remedy is therefore a fundamental change to eliminate inappropriate discrimination in the institutional policies and practices. This trend has implications on the performance and academic development of females in academia. Female academics, for instance, have, over time, published less than their male counterparts. This is echoed in an Australian study of early career researchers in which it was found that males had a significantly higher total publication index than females (Gardner et al 1998). It has also been found that women's research and publication output in Nigerian academy is lower than those of their male counterparts. Ogbogu (2006) confirmed that women publish between one and two papers on the average annually, while the majority of them do not publish at all on an annual basis. 
The observed gender disparity in academia is further shaped by educational credentials. Women, on average, are less likely to have doctorates and those who have it in the system are under-represented as full professors (National Centre for Education Statistics, 2009). Consequently, female academics are less included, respected, and valued as researchers and are likely to be taken less seriously than men. In addition to this, marital and parental status accentuates gender inequalities. This is because men are less likely to be responsible for family care needs. A number of scholars argue that the scheduling of work and structure of workplaces are built around a model of an 'ideal worker' who is relatively unencumbered by responsibilities outside of paid labour, best represented by a man with a wife at home to manage family responsibilities. In support of this, Cress and Hart (2009) and Williams (2000) affirm that academia is built on a male worker norm because women faculty report being looked down upon as less qualified or committed to academics because they have families. Thus, the likelihood of successfully marching through the lockstep life course of a traditional academic career is much greater for those not encumbered by family demands (Mason and Goulden, 2002).

Research and publication, which men engage in to a greater extent, receive higher rewards than teaching, which women devote more time to. Consequently, women tend to occupy the lower position of the academic career structure than their male counterparts. Postkitt (1999) is, however, of the view that the reward system was established by men and structured to favour them so that rewards go primarily to them and to those women who share their views on the criteria for academic rewards. Postkitt (1999) further asserted that women in academia experience reduced opportunity to direct a research project and proper funding for educational work. For instance, women applying for post doctoral research fellowships from the Swedish medical research council had to be 2.5 times more productive than the male applicants to get the same rating for scientific competence. He therefore concluded that women's subordination in academia is part of an overall social system in which women remain subordinate to men. Poskitt (1999) thus supports the ideals of the feminist liberal theorists who affirm that the society and the belief in patriarchy act as agents of oppression for females. They believe that men and women are created equally, therefore the rights of men should be extended to the female folks. Hakim's preference theory (2000) opposes the views of the liberalists. He posits that recent advances have given women 'genuine choices' for the first time and that any residual gender gaps in the labour market experiences and outcomes are the result of gender-differentiated preferences, with institutional constraints relevant only at the margins. Although there is evidence among university faculty that women have higher motivations for teaching, Bailey (1999) affirms that men are more heavily oriented toward research. Strictly, preference-based approaches, such as Hakim's theory, fail to acknowledge the extent to which men's and women's preferences, far from being solely a reflection of individual desires, are constrained by structural and societal factors (Schuster and Finkelstein, 2006).

Academics and institutions of higher learning like to think of themselves as liberal and open-minded. They claim to support the cause of social justice for all, yet their modes of governance and administrative structures, the gender imbalance of their institutions, and their teaching and research activities, as evident in Postkitt's work, do not reflect what they preach. Attempts should be made by Nigerian universities to respond to the evidence-based gender disparity by institutionalizing gender equity principles and practices needed to increase the full participation of women in academia in the face of a rapidly globalizing and complex world system.

\section{METHODS}

The study was conducted in three federal universities located in Southwestern Nigeria - Obafemi Awolowo University, University of Ibadan, and the University of Lagos. The three universities are some of the first generation universities established in Nigeria in the 1960s. The data in this paper were derived from both primary and secondary sources. Secondary data were drawn from accounts of published and unpublished materials. Primary data were generated from qualitative face-to-face in-depth interviews of 60 purposively selected male (30) and female (30) academic staff in the categories of Deans, Heads of Departments and Senior Lecturers. Although the respondents interviewed do not necessarily reflect the overall campus population, they were selected based on their experience and knowledge of gender issues in the universities. Each interview began with open-ended questions and lasted from one to two hours, and the respondents' answers also shaped the direction of each conversation. The responses were recorded and transcribed after which they were coded using the ZY index table as a basis for analysis. The salient themes that emerged from the analysis are reported below. 


\section{RESULTS AND DISCUSSION}

\section{Causes of Gender Inequality in Academia}

The opinions of respondents on the causes of gender inequality in academia are recorded in Table 1:

Table 1

Respondents' Opinions on the Causes of Gender Inequality in Academia

\begin{tabular}{|c|c|c|c|c|c|c|}
\hline \multirow{2}{*}{ Responses } & \multicolumn{2}{|c|}{ Deans } & \multicolumn{2}{|c|}{ Heads of Departments } & \multicolumn{2}{|c|}{ Senior Lecturers } \\
\hline & Male & Female & Male & Female & Male & Female \\
\hline More males possess doctorate degrees. & ++ & ++ & ++ & ++ & ++ & ++ \\
\hline $\begin{array}{l}\text { Lengthy period of training for the job } \\
\text { discourages women. }\end{array}$ & + & - & + & + & + & + \\
\hline Poor remuneration. & + & + & + & + & + & + \\
\hline Women's lack of interest. & + & + & + & + & + & - \\
\hline $\begin{array}{l}\text { The belief that academics is a masculine } \\
\text { job. }\end{array}$ & - & - & + & - & + & - \\
\hline Lack of mentoring. & + & + & - & + & - & + \\
\hline Marriage. & + & + & + & + & + & + \\
\hline Total number of respondents & 9 & 2 & 9 & 9 & 12 & 19 \\
\hline
\end{tabular}

Key:

$++=$ Cases where opinion is strongly expressed.

$+\quad=$ Cases where opinion is expressed.

$-\quad=$ Cases where opinion is not expressed.

Data in Table 1 reveal respondents' opinions on the causes of gender inequality in academia. Results show that all the respondents strongly expressed the view that more males than females possess doctorate degrees. This confirms Kan's (2007) assertion that gender disparity in academia is shaped by educational credentials and Rahji's (2001) views that the acquisition of doctorates enable women to gain access into academia and advance in it. This finding invariably implies that the gap is driven by the lower likelihood of females having doctorate degrees. This supports the fact that the recruitment and selection practices in universities do not discriminate against women; rather inclusion is based on merit.

The table further shows that all the respondents, with the exception of the female Dean, opined that the lengthy period of training required to obtain a doctorate and qualify as an academic discourages women and it is thus a major cause of the observed gender inequality. The respondents further explained that women would most often prefer to pick up lucrative jobs outside of academia and possibly get married after obtaining a bachelors degree than to continue with postgraduate studies.

Gender inequality in Nigerian universities was attributed to poor remuneration of academic staff. This opinion cuts across all the respondents interviewed. This may be due to the fact that income is a major variable that significantly attracts new entrants into a profession and also influences job satisfaction and staff retention. Hence, Robbins (1998) affirmed that economic wages and other appropriate organizational incentives are vital to staff retention.

Furthermore, data in the table reveal that all the respondents, with the exception of the female Senior Lecturers, identified 'lack of interest' as a major variable impeding female participation in academia. Explanations derived from the conversations with the respondents show that most women lack interest in academia because of the rigorous nature of research work. This result agrees with Gujarati's (2004) findings that though women have a high need for achievement, they lack interest in active research and publish less than men. 
The belief that the academic profession is a masculine job was an opinion which did not cut across all the respondents. This view was only provided by the male Heads of Departments and Senior Lecturers interviewed. The female respondents were silent on this issue, which probably implies that women are comfortable with the job schedules in academia. This opinion, however, contradicts that which is expressed in most literature on gender inequalities. For instance, Ristad and Rigstad (2007) perceive academia as a masculine job that is patriarchal in nature and which has a glass ceiling of unstated norms that hinder women's effective participation and advancement in the system. Williams (2000) affirms that academia is built on a male worker norm with job schedules built around a model of an 'ideal worker' who is unencumbered by responsibilities outside of paid labour. Males are thus empowered and have more power which avails them access to resources and facilities.

Lack of mentoring for the younger female academics was identified as a major indicator of disparity in academia by all the respondents with the exception of the male Heads of Departments and Senior Lecturers. Mentoring has a network-building effect, increases self-confidence, creates career awareness and promotes progression in personal work. The female respondents agreed that mentoring is a useful tool in climbing the academic ladder and also an outlet for the mentees to release their frustrations of all the barriers and realities working against them in the system. They concluded that mentors help to overcome gender inequalities and unequal opportunities because of the networking that the relationship often provides. Since there continues to be lack of female role models and mentors in Nigerian academia, the female respondents expressed fear that the gender inequality in academia would persist for a long time to come.

Marriage was predicted to be a major cause of gender inequality in Nigerian academia. This consensus opinion by all the respondents was accentuated by the fact that females experience high institutional mobility and some have had to relocate and disengage from academia in order to join their husbands because the job of their husbands take precedence over theirs. Marriage and its accompanying responsibilities of parenthood constitute more problems to women than men in attaining continuity in their research work. This accounts not just for the inequality in number, but also for the difference in the rates of progression in academic careers of males and females.

Generally, results in Table 1 offer an explanation for the observed gender inequality in Nigerian academia.

\section{Consequences of Gender Inequality on the Academic Development of Females}

The opinions of respondents on the consequences of gender inequality on the academic development of females are recorded in Table 2:

Table 2

Respondents' Opinion on the Consequences of Gender Inequality on the Academic Development of Females in Academia

\begin{tabular}{|c|c|c|c|c|c|c|}
\hline \multirow{2}{*}{ Responses } & \multicolumn{2}{|c|}{ Deans } & \multicolumn{2}{|c|}{ Heads of Departments } & \multicolumn{2}{|c|}{ Senior Lecturers } \\
\hline & Male & Female & Male & Female & Male & Female \\
\hline $\begin{array}{l}\text { General reduction in the promotion of } \\
\text { female research work. }\end{array}$ & ++ & ++ & ++ & ++ & ++ & ++ \\
\hline $\begin{array}{l}\text { Few women would continue to feature } \\
\text { in academia. }\end{array}$ & + & + & + & + & + & + \\
\hline $\begin{array}{l}\text { Women would continue to be } \\
\text { disadvantaged due to poor mentoring. }\end{array}$ & - & + & - & + & - & + \\
\hline $\begin{array}{l}\text { Women would continue to occupy the } \\
\text { lower positions in the academic } \\
\text { profession. }\end{array}$ & - & + & - & + & - & + \\
\hline Total number of respondents & 9 & 2 & 9 & 9 & 12 & 19 \\
\hline
\end{tabular}

Key:

$++=$ Cases where opinion is strongly expressed.

$+=$ Cases where opinion is expressed.

$-=$ Cases where opinion is not expressed 
Data in Table 2 indicate that all the respondents expressed the view that a general reduction in the promotion of female research work is a major consequence of gender inequality. They further indicated that an increase in the population of senior female academics would result in a general increase in the research output of females because their senior colleagues would be available to build a network of support for them. This view reiterates Siemienska's (2007) findings that the research productivity of women in academia was lower than that of men in Poland. Ogbogu (2009a), in support of this, found that females in Nigerian universities engaged more in teaching activities than in research work. The respondents interviewed attributed this to a legacy of gender inequality in occupational opportunity. This puts women at a disadvantaged position because research and publication are the major criteria for promotion in academia. The respondents interviewed explained further by attributing this to the fact that women perceive teaching as realistic options because of a legacy of gender inequalities in academia.

Data in the table show that another major consequence of the observed gender inequality expressed by all the respondents is that few women would continue to be featured in academia. They expressed the fear that by this trend, women would not be able to constitute a 'critical mass' in decision-making positions to influence policies that affect their career progression. The implication of this consensus opinion is that academia would remain a maledominated profession for a long time to come and women would remain excluded from the benefits of the patriarchal support system that promotes powerful informal networking.

Furthermore, all the female respondents, with the exception of the males, opined that women would continue to remain disadvantaged and most likely exit academia because of the presence of few senior female academics, who ought to serve as mentors to the graduate students and junior academic staff so that they can be encouraged to progress with postgraduate studies and advance in academia. Availability of mentors would help overcome gender inequalities and unequal opportunities because of the networking that the relationship often provides.

The respondents concluded that women would continue to occupy the lower positions in academia while their male counterparts occupy the decision-making positions in the universities. This is because males have power at their disposal to make decisions that affect them. Although the paucity of women in senior academic positions is indicative of a culture that is unfriendly to women, the female interviewees characterized their universities as nondiscriminatory toward women despite their inferior number in the top positions. Specifically, the respondents from Obafemi Awolowo University indicated that their university has come up with a Gender Policy Document to advance equal opportunity for the female staff. Wenneras and Wolds (1997) provide an explanation for this trend of opinions by affirming that although women encounter discrimination in the university, they fail to recognize it because the university is perceived as an institution that emphasizes objectivity, fairness, the pursuit of knowledge and merit as a basis of evaluation. As a result, women who experience discrimination may not only fail to recognize it, but will come up with some explanation for differential treatment and thereby deny the existence of discrimination at all.

Generally, results in Table 2 show that women expressed more concern about the implications of gender inequality on the academic development of females. With this being the case, women should be empowered through various programmes to meet their demand for increased representation, equality and retention in academia. This is vital because their prominence in academia would equip Nigerian universities to act as a catalyst for sustainable development in a rapidly globalizing world.

\section{CONCLUSION}

This study has shown that the observed gender inequality in academia is a perennial problem which will persist for a long time to come. It is evident that although universities see themselves as liberal and open-minded, their administrative and decision-making systems remain patriarchal and male dominated. There are not enough corresponding structures or policies in Nigerian universities that support gender equity in academia. This paper maintains that women primarily encounter obstacles on their way to the top of the academic career ladder, which further accounts for the persistence of sex disparity in academia. In addition, it was found that lack of mentoring, poor remuneration, women's lack of interest in academia, family responsibilities and the lengthy period of training 
accounted for the observed gender inequality in academia. Although the study indicates that the academic profession is not perceived by respondents as a masculine job, evidences from literature indicate that subtle informal relations of power amongst the men or a 'glass ceiling' exists and influences the selection and promotion processes.

The implications of the observed inequalities on the academic development of women is the general reduction in their research and publication output which accentuates the perpetuation of their low status in academia. Their low status in academia does not encourage mentoring nor suffice in building network of support, which is a valuable and fundamental development strategy in academia. The study concluded that appropriate institutional adjustments and affirmation action programmes are necessary in improving retention and in meeting women's demand of equality.

\section{AUTHOR INFORMATION}

Christiana O. Ogbogu lectures Public Administration in Obafemi Awolowo University, Nigeria. Her doctorate degree dissertation evaluated the labour input of females in Nigerian public universities. Her research interests include: gender analysis in cross cutting issues in Public Administration, higher educational administration and human resource management. Her research work project ways in which institutional capacities can be harnessed in developing and sustaining gender sensitive policies that would enhance gender equality in the work place. The results of her research activities have been published in reputable journals and they have also been presented in both local and international conferences. E-mail: tinaogbogu@yahoo.com

\section{REFERENCES}

1. $\quad$ Adler, L. (1991). Women in Cross Cultural Perspective. New York: Praeger.

2. Bailey, J. G. (1999).Academics' motivation and self-efficacy for teaching and research. Higher Education research and development. Vol. 18 (3):343-359.

3. Cress, C. and Hart, J. (2009).Playing Soccer and Football Field: The persistence of Gender inequalities for women faculty. Equity and Excellence in Education. Vol.42 (4): 473-488

4. Gardner, M., Edwards, A. \& Ramsey, E. (1988). Women in Australian Universities: Findings from Recent Research and Policy Implications. Paper Presented at 1998 Australian Vice-Chancellor's Committee Retreat.

5. $\quad$ Gujarati, D. (2004). Basic Econometrics. New York: McGraw-Hill

6. Hakim, C. (2002).Lifestyle preferences as determinants of women's differential labour Market careers. Work and Occupations. Vol.29 (4):428-459.

7. Kan, M. (2007).Work orientation and wives' employment careers: An evaluation of Hakim's preference theory. Work and Occupations. Vol. 34(4): 430-462.

8. Luke, C. (1997). Quality Assurance and Women in Higher Education. Higher Education. Vol. 33 (2): $433-$ 451.

9. $\quad$ Mason, M and Goulden, M.(2002).Do babies matter? Academe.Vol.88 (6):21-27.

10. Morley, L. (1999). Organizing Feminism: The Micro politics of the Academy. New York: St. Martins.

11. National Centre for Education Statistics. (2009).Digest for education statistics:2009.http://nces.ed./gov/programs/digest/do9/ (accessed May, 2010).

12. Obafemi Awolowo University, (2006). University Calendar. Ile-Ife: Obafemi Awolowo University Press.

13. Ogbogu, C. O. 2006. An Evaluation of Female Labour Input in the Nigerian University Educational System. Unpublished Doctoral Dissertation, Obafemi Awolowo University, Ile-Ife, Nigeria.

14. Ogbogu,C. O. (2009a).An Analysis of Female Research productivity in Nigerian Universities. Journal of Higher Education Policy and Management. Vol 31 91):17-22.

15. Ogbogu, C. O. (2009b). An Assessment of the Institutional Factors Affecting Female Labour Input in the Nigerian University System. Asian Women. Vol. 25(1): 55-74.

16. Okurama, D. E. (2008). 'Mentoring in the Nigerian Academia: Experiences and Challenges.' International Journal of Evidence based Coaching and Mentoring. Vol. 6(1): 45-56.

17. Poole, M. (2005). Removing the Equality Barriers: Women as Senior Managers and Executives in Universities. Paper Presented at the International Association of University Presidents, 2005 XIV Trennial Conference, Bangkok, Thailand. 
18. Postkitt, E. (1999). Women in Higher Education. University System News. Vol. 9(2):34-56

19. Rahji, M. (2001). Gender Productivity Differentials and Returns to Schooling in Farm Households in Southern Nigeria. Nigeria Agricultural Development Studies. Vol. 2(1): 13-21.

20. Ristad, L. and Rigstad, M. (2007). Gender Balance in Higher Education and Research: Golden Opportunities. Final Report from the Committee for Mainstreaming Woman in Science, Norway.

21. Robbins, S. P. (1998).Organizational Behaviour Concepts, Controversies and Applications. London: Prentice Hall.

22. Schuster, J. and Finkelstein, J. (2006).The American faculty: The restructuring of Academic Work and Careers. Baltimore: John Hopkins University.

23. Siemienska, R. (2007). The Puzzle of Gender Research Productivity in Polish University. In Castle, M (Ed.) Gendered Career Trajectories in Academia in Cross-National Perspective, (pp.241-264) Poland: Paper and Tinta.

24. Williams. (2000). Unbending Gender: Why family and work conflict and what to do about it. New York: Oxford University Press.

25. Winslow, S. (2010).Gender inequality and time allocations among academic faculty. Gender and Society. Vol.24 (6): 769-793. 